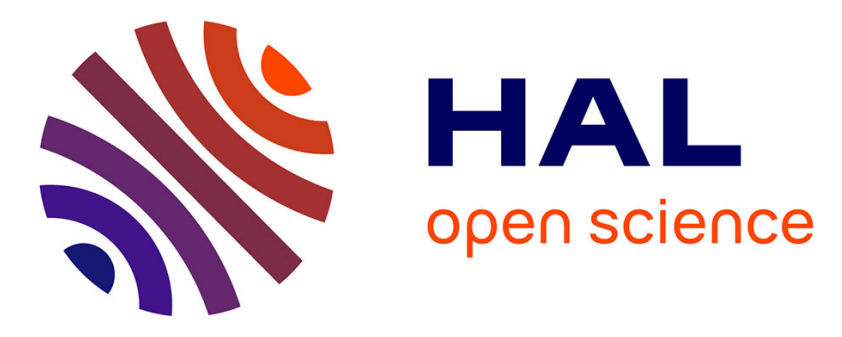

\title{
Sleep aspects on video-polysomnography in LRRK2 mutation carriers
}

\author{
Mickael Ehrminger, Smaranda Leu-Semenescu, Florence Cormier, \\ Jean-Christophe Corvol, Marie Vidailhet, Eden Debellemaniere, Alexis Brice, \\ Isabelle Arnulf
}

\section{To cite this version:}

Mickael Ehrminger, Smaranda Leu-Semenescu, Florence Cormier, Jean-Christophe Corvol, Marie Vidailhet, et al.. Sleep aspects on video-polysomnography in LRRK2 mutation carriers. Movement Disorders, 2015, 30 (13), pp.1839-1843 10.1002/mds.26412 . hal-01218069

\section{HAL Id: hal-01218069 https: / hal.sorbonne-universite.fr/hal-01218069}

Submitted on 23 Oct 2015

HAL is a multi-disciplinary open access archive for the deposit and dissemination of scientific research documents, whether they are published or not. The documents may come from teaching and research institutions in France or abroad, or from public or private research centers.
L'archive ouverte pluridisciplinaire HAL, est destinée au dépôt et à la diffusion de documents scientifiques de niveau recherche, publiés ou non, émanant des établissements d'enseignement et de recherche français ou étrangers, des laboratoires publics ou privés. 


\section{Sleep aspects on video-polysomnography in LRRK2}

\section{mutation carriers}

Mickael Ehrminger, ${ }^{1,2,4}$ Smaranda Leu-Semenescu, ${ }^{2,4}$ Florence Cormier, ${ }^{3,4}$ Jean-

Christophe Corvol, ${ }^{3,4}$ Marie Vidailhet, ${ }^{3,4}$ Eden Debellemaniere, ${ }^{4}$ Alexis Brice, ${ }^{3,4}$ Isabelle Arnulf ${ }^{2,4}$

1- Ecole Normale Supérieure, Paris, France AP-HP

2- APHP, Pitié-Salpêtrière Hospital, Sleep Disorders Unit, Paris, France

3- APHP, Pitié-Salpêtrière Hospital, Neurology Department

4- Sorbonne Universities, UPMC Univ Paris 06, INSERM UMR_S1127, CIC-1422,

CNRS, UMR_7225, ICM, Paris, F-75013 Paris, France.

Correspondence to: Pr I. Arnulf, Service des pathologies du sommeil, Hôpital Pitié Salpêtrière, 47-83 boulevard de l'Hôpital, 75651 Paris Cedex 13, France

Tel: 33 (0)1 42167702 / Fax: 33 (0) 142167700

E-mail: isabelle.arnulf@psl.aphp.fr

Manuscript content: Abstract: 150 words. Body text: 1700 words, 2 tables, 1 Supplemental table, 36 references.

Running title: Sleep in LRRK2 mutation 
Key words: Parkinson's disease, genetic, REM sleep behavior disorder, periodic leg movements, sleepiness

Conflict of Interest Disclosures: The authors have no conflict of interest with regard to the present study.

Funding and Support: The LRRK2 study was supported by INSERM. The control groups were financed by Agence Nationale de la Recherche (ANRMNP 2009, Nucleipark), DHOS-Inserm, France Parkinson, Ecole Neuroscience de Paris, “Investissements d'avenir" (ANR-10-IAIHU-06), Institut Hospitalo-Universitaire de Neurosciences-ICM Pitié-Salpêtrière. The funding sources had no role in the design and conduct of the study; collection, management, analysis, and interpretation of the data; preparation, review, or approval of the manuscript; or decision to submit the manuscript for publication.

Report submitted to: Movement Disorders Journal

Type of article: Brief Report

Version: 3 


\section{Abstract}

Background: Rapid eye movement sleep behavior disorder and sleepiness precede or accompany idiopathic Parkinson's disease (PD), but their presence in subjects with leucine-rich repeat kinase 2 (LRRK2) mutations is unknown.

Methods: Ten patients with LRRK2-associated PD, 4 healthy LRRK2 mutation carriers, 20 patients with idiopathic PD and 12 healthy controls underwent clinical assessments, and a nighttime video-polysomnography.

Results: There were no sleep changes, no rapid eye movement sleep behavior disorder or rapid eye movement sleep without atonia in the 14 subjects with LRRK2 mutations compared with controls, while $41 \%$ of patients with idiopathic PD had rapid eye movement sleep behavior disorder. Eventually, $20 \%$ of patients with LRRK2associated PD had abnormal periodic leg movements, a frequency similar to the idiopathic PD group frequency.

Conclusions: The sleep phenotype in LRRK2 mutations parallels that of idiopathic $\mathrm{PD}$, except for absent rapid eye movement sleep behavior disorder here in the presymptomatic and symptomatic stages 


\section{INTRODUCTION}

Mutations in the LRRK2 (leucine-rich repeat kinase 2) gene, which codes for dardarine, may cause Parkinson disease (PD). ${ }^{1,2}$ The single mutation Gly2019Ser is associated with $3-6 \%$ of the familial PD forms and $2 \%$ of sporadic PD in Europe, ${ }^{3-6}$ and $37 \%$ of familial PD in Africa. Healthy carriers have been identified in families with LRRK2 mutations. The transmission is autosomal dominant, but the penetrance of parkinsonism varies from $28 \%$ at age 59 to $74 \%$ at age 79 for G2019S mutation. ${ }^{7}$ Compared to idiopathic PD, the LRRK2 patients have a less marked, asymmetrical and tremor-predominant type of parkinsonism, with less frequent cognitive and olfactory deficits, but more frequent psychiatric symptoms (depression, anxiety, and irritability). ${ }^{7-10}$

Sleep problems are frequent in LRRK2-associated PD, as 69\% of 268 mutated patients complain of disturbed sleep (single question). ${ }^{7}$ Healthy mutation carriers report shorter sleep time than non-carriers. ${ }^{11}$ Sleep disturbances are also prevalent in idiopathic PD, including insomnia, REM sleep behavior disorder (RBD, a condition characterized by violent, enacting dreams plus REM sleep without atonia), ${ }^{12}$ sleepiness, restless legs syndrome and periodic limb movements. ${ }^{13}$ Notably, sleepiness and RBD can predate the onset of parkinsonism by several years. ${ }^{14-17}$ The presence of RBD in the first years of PD confers a high risk of later developing dementia. $^{18}$

To date, no study has systematically investigated the sleep phenotype associated with LRRK2 mutations using formal sleep monitoring. Because healthy carriers may have sleep markers predicting phenoconversion to parkinsonism, we systematically studied the video-polysomnography in patients with LRRK2-associated 
PD vs. patients with idiopathic PD, and in healthy LRRK2 mutation carriers vs. healthy controls.

\section{METHODS}

We invited all patients with LRRK2 mutations and their relatives on the list of the French PD Genetics Network to participate in a phenotype study. Patients had defined parkinsonism ${ }^{19}$ and a mutation in the LRRK2 gene (G2019S, R1441H). Healthy LRRK2 mutation carriers were selected among their first-degree relatives. They carried the gene mutation (but ignored it), and had no sign of neurological disorder. Patients with idiopathic PD matched for age, sex, and disease duration were selected from another program, with no selection regarding sleep disturbances. $^{20}$ They met PD criteria ${ }^{19}$ and had a sporadic disease. Healthy controls included the non-mutated first-degree healthy relatives of LRRK2 patients $(n=5)$ and healthy controls $(n=7)$, matched for age and sex with healthy LRRK2 mutations carriers, and examined by neurologists to rule out any neurological disorder. All participants signed an informed consent for the study, which was approved by the ethical committee.

The motor disability was evaluated of at the time of the best effect of the dopaminergic treatment, using the Unified PD rating scale-III. ${ }^{21,22}$ All participants and bed partners were interviewed about agitating nightmares and completed the Epworth sleepiness scale. ${ }^{23}$ They underwent a video-polysomnography including EEG, electro-oculography, nasal pressure and respiratory efforts, electrocardiography, oximetry, chin and bilateral legs EMG, and infrared video-sound monitoring. The recordings were visually scored blinded to the neurological and genetic status, using international rules. ${ }^{24}$ The autonomic activity was measured 
using an analysis of the R-R cardiac interval on the EKG during the night (Medatec®, France). The mean, standard deviation and coefficient of variation (the ratio of the SD to the mean, an indicator of signal variability) of heart rate was obtained in 5 minutes long epochs of stable, quiet wake (eye closed), stable N2, stable N3 and stable REM sleep. $^{25}$

Measures were compared between matched groups (LRRK2-associated PD versus sporadic PD groups and healthy LRRK2-mutation carriers versus healthy controls) using the Wilcoxon rank test (continuous values) and Fisher's exact test (discrete values), with a significant $p$ below 0.05 .

\section{RESULTS}

There were two patients with a mutation in the $\mathrm{R} 1441 \mathrm{H}$ part of the LRRK2 gene and eight patients and four healthy carriers with a mutation in the G2019S part of the LRRK2 gene. The body mass index and scores on the Epworth sleepiness scale were higher in the LRRK2 healthy carriers than in the control groups (Table 1). The motor disability and dopaminergic treatment were not different in the LRRK2associated PD than in the with idiopathic PD groups. The sleep measures were not different between groups (Table 2). There was no REM sleep without atonia in LRRK2-mutated subjects independent of whether they already had PD. None of the subjects with LRRK2 mutations had "any" tonic or phasic enhanced chin muscle activity during more than $18 \%$ of REM sleep, while this was the case in $13(65 \%)$ patients with idiopathic PD, of whom only 7 took an antidepressant. The remaining 6 patients with PD taking an antidepressant had no RBD or REM sleep without atonia. The percentages of phasic and tonic REM sleep without atonia were higher in idiopathic than in LRRK2-associated PD groups. Eventually, when combining clinical 
and polysomnographic RBD criteria, none of the 14 subjects with LRRK2 mutations had a defined RBD, vs. 9 (45\%) patients with idiopathic PD (4 patients with idiopathic PD had isolated REM sleep without atonia). There were behaviors during REM sleep on the video analysis in 8 patients with idiopathic PD and in no patient with a LRRK2 mutation. The periodic leg movement index and associated arousal index, as well as the frequency of abnormal periodic leg movements ${ }^{26}$ were not different between groups. The analysis of the variability of the $\mathrm{R}-\mathrm{R}$ cardiac interval did not yield any difference between groups, whatever the sleep stage (Supplemental Table).

\section{DISCUSSION}

The 14 subjects with LRRK2 mutations studied with sleep tests had no major sleep changes when compared with matched controls (healthy controls or patients with idiopathic PD). Notably, none of the subjects with LRRK2 mutations had any defined RBD or REM sleep without atonia (a preclinical stage of RBD). Patients with LRRK2associated PD had a variability of the heart rate during wake and sleep similar to the other groups' variability.

To the best of our knowledge, there has not been any previous systematic study of sleep structure and motor activity in subjects with LRRK2 mutations, but only questionnaire-based studies. ${ }^{7,}{ }^{11}$ We did not find an abnormal subjective sleepiness in 10 patients with LRRK2-associated PD, in accordance with previous data. ${ }^{10}$ In this context, the increased level of sleepiness in our LRRK2 mutation healthy carriers (but not in those with PD) may correspond to random fluctuation, rather than to a robust early marker of neurodegeneration. However, a limitation here is that we did not perform multiple sleep latency tests, which may detect an abnormal propensity to fall asleep in some patients with PD denying any subjective sleepiness. ${ }^{27}$ 
Reduced or fragmented sleep was frequently reported on questionnaires among patients with LRRK2 mutations, ${ }^{7}$ but there was no significant difference with patients with idiopathic PD when the sleep disturbances were stratified by disease duration or by mutation, suggesting that parkinsonism (and its motor consequences during the night, including difficulties turning in bed, readjusting blankets, urinating, pain and tremor) rather than the LRRK2 gene causes interrupted sleep. Therefore, patients with LRRK2 mutations and subclinical parkinsonism report the same usual nighttime sleep time than non-mutation carriers. ${ }^{10}$ The objective measures of sleep time and fragmentation in our study support this view, as sleep latencies, total sleep time, sleep efficacy, and arousal index were not different in subjects with LRRK2 mutations than in matched controls.

The absence of defined RBD and REM sleep without atonia in 14 subjects with LRRK2 mutations independent of whether they were presymptomatic or symptomatic is a strong finding in our cohort. In contrast, RBD was frequent $(45 \%)$ in patients with idiopathic $\mathrm{PD}$, as it is the case in $\mathrm{PD} .^{28,29}$ This result may rule out the concept of concomitant RBD in presymptomatic LRRK2-associated PD, at least around age 40, and suggests that RBD, if present in some patients with LRRK2 mutations as occasionally mentioned using non-systematic sleep studies in a large cohort of 268 patients, ${ }^{7}$ is a rare occurrence. Similarly, among 32 LRRK2 carriers with mild parkinsonism, a single mutated patient with dream-enacted behavior was suspected of clinical RBD. ${ }^{11}$ Nevertheless, one may keep in mind that dream-enacted behavior may also correspond to adult sleepwalking ${ }^{30}$ or confusional arousals caused by apnea, sleep deprivation or drugs. ${ }^{31}$ As a consequence, robust diagnostic criteria, including frequent behaviors plus video-polysomnography with REM sleep without atonia are mandatory for defining RBD. Eventually, patients with frequent dream- 
enacted behaviors in cohorts of mutation carriers should be studied with videopolysomnography to determine whether RBD is definitively absent at the preparkinsonism stage and instead develops with age (when penetrance increases) or longer parkinsonism. In contrast, despite the fact that LRRK2 patients had a similar disease course and motor disability than those with idiopathic PD, they seemed to be protected from RBD. This result, together with the better autonomic function during REM sleep in patients with LRRK2 than with idiopathic PD (whereas it is altered in idiopathic RBD), ${ }^{25}$ support the concept that LRRK2-associated PD is a unique subtype of PD. Notably, LRRK2 patients have a lower risk of developing dementia than patients with idiopathic PD. ${ }^{7-10}$ Because RBD strongly predicts dementia in idiopathic $\mathrm{PD},{ }^{18}$ and is associated with cholinergic loss, ${ }^{32}$ one may wonder whether absent RBD and rare dementia in LRRK2 patients may result from a similar pathophysiology, e.g., a lower loss of cholinergic neurons. RBD seems to be rare in some other genetic parkinsonisms, including patients with two parkin mutations, ${ }^{33}$ and a family with PINK1-associated parkinsonism. ${ }^{34}$ However, it was found in two brothers with DJ-1 mutations. ${ }^{35}$ Plus, idiopathic RBD and the risk of earlier conversion to synucleinopathy have been recently associated with a subset of PDassociated genes. ${ }^{36}$

The main limitation of our study is the limited sample size (especially the LRRK2 healthy carriers). However, the LRRK2 mutation is a rare genetic mutation mostly present in North Africa: patients have to travel to France for the study. We tried to circumvent this bias by matching the LRRK2 groups with larger control groups. The sample size is counterbalanced by the objective findings obtained during videopolysomnography, a sensitive procedure difficult to perform in large cohorts. 
In conclusion, no LRRK2-specific sleep phenotype was identified in this systematic study. Instead, the sleep structure in LRRK2-associated PD parallels that of idiopathic PD, except for absent RBD. Since no presymptomatic RBD was found in patients with LRRK2 mutations, RBD cannot be used as surrogate, early markers of neurodegeneration in future neuroprotective interventions in LRRK2 healthy carriers.

Acknowledgements: We thank Suzanne Lesage and Cécile Cazeneuve for the LRRK2 genotyping and the French Parkinson's disease genetics network (PDG) for its contribution to the recruitment of patients.

Authors' Role: I. Arnulf takes responsibility for the integrity of the data and the accuracy of the data analysis. Research project: Conception: A. Brice, JC. Corvol, I. Arnulf; Organization: JC. Corvol, I. Arnulf. Execution: F. Cormier, S. Leu-Semenescu, M. Ehrminger, M. Vidailhet. Statistical Analysis: Design and Execution: M. Ehrminger; Review and Critique: I. Arnulf. Manuscript Preparation: Writing of the first draft: M. Ehrminger, I. Arnulf; Review and Critique: all authors.

Financial Disclosures out of this work: Dr Arnulf has been a consultant and invited speaker for UCB Pharma. Dr Leu-Semenescu has been an invited speaker and was invited to congresses by UCB Pharma. Dr Corvol received honoraria or travel grants from Teva, Lundbeck, Novartis, UCB, Sanofi, and research grants from INSERM, the French Ministry of Health, and the Michael J Fox Foundation. Alexis Brice received 
honoraria from the Wolfson Foundation for reviewing the scientific project. He also received honoraria from Lundbeck for giving a talk. 


\section{References}

1. Paisan-Ruiz C, Jain S, Evans EW, et al. Cloning of the gene containing mutations that cause PARK8-linked Parkinson's disease. Neuron 2004;44:595-600.

2. Zimprich A, Muller-Myhsok B, Farrer M, et al. The PARK8 locus in autosomal dominant parkinsonism: confirmation of linkage and further delineation of the disease-containing interval. American journal of human genetics 2004;74:11-19.

3. Nichols WC, Pankratz N, Hernandez D, et al. Genetic screening for a single common LRRK2 mutation in familial Parkinson's disease. Lancet 2005;365:410-412.

4. Di Fonzo A, Rohe CF, Ferreira J, et al. A frequent LRRK2 gene mutation associated with autosomal dominant Parkinson's disease. Lancet 2005;365:412-415.

5. Lesage S, Ibanez P, Lohmann E, et al. G2019S LRRK2 mutation in French and North African families with Parkinson's disease. Ann Neurol 2005;58:784-787.

6. Lesage S, Janin S, Lohmann E, et al. LRRK2 exon 41 mutations in sporadic Parkinson disease in Europeans. Arch Neurol 2007;64:425-430.

7. Healy DG, Falchi M, O'Sullivan SS, et al. Phenotype, genotype, and worldwide genetic penetrance of LRRK2-associated Parkinson's disease: a case-control study. Lancet Neurol 2008;7:583-590.

8. Aasly JO, Toft M, Fernandez-Mata I, et al. Clinical features of LRRK2associated Parkinson's disease in central Norway. Ann Neurol 2005;57:762-765.

9. Alcalay RN, Mejia-Santana H, Tang MX, et al. Self-report of cognitive impairment and mini-mental state examination performance in PRKN, LRRK2, and GBA carriers with early onset Parkinson's disease. J Clin Exp Neuropsychol 2010;32:775-779.

10. Kalia LV, Lang AE, Hazrati LN, et al. Clinical correlations with Lewy body pathology in LRRK2-related Parkinson disease. JAMA Neurol 2015;72:100-105. 
11. Johansen KK, White LR, Farrer MJ, Aasly JO. Subclinical signs in LRRK2 mutation carriers. Parkinsonism Relat Disord 2011;17:528-532.

12. Arnulf I. REM sleep behavior disorder: motor manifestations and pathophysiology. Mov Disord 2012;27:677-689.

13. De Cock VC, Vidailhet M, Arnulf I. Sleep disturbances in patients with parkinsonism. Nat Clin Pract Neurol 2008;4:254-266.

14. Abbott RD, Ross GW, White LR, et al. Excessive daytime sleepiness and subsequent development of Parkinson disease. Neurology 2005;65:1442-1446. 15. Iranzo A, Tolosa E, Gelpi E, et al. Neurodegenerative disease status and postmortem pathology in idiopathic rapid-eye-movement sleep behaviour disorder: an observational cohort study. Lancet Neurol 2013;12:443-453.

16. Postuma RB, Gagnon JF, Vendette M, Fantini ML, Massicotte-Marquez J, Montplaisir J. Quantifying the risk of neurodegenerative disease in idiopathic REM sleep behavior disorder. Neurology 2009;72:1296-1300.

17. Schenck CH, Boeve BF, Mahowald MW. Delayed emergence of a parkinsonian disorder or dementia in $81 \%$ of older males initially diagnosed with idiopathic REM sleep behavior disorder (RBD): 16year update on a previously reported series. Sleep Med 2013;14:744-748.

18. Anang JB, Gagnon JF, Bertrand JA, et al. Predictors of dementia in Parkinson disease: A prospective cohort study. Neurology 2014;83:1253-1260.

19. Hughes A, Daniel S, Kilford L, Lees A. Accuracy of clinical diagnosis of idiopathic Parkinson's disease: a clinico-pathological study of 100 cases. J Neurol Neurosurg Psychiatry 1992;55:181-184. 
20. Garcia-Lorenzo D, Longo-Dos Santos C, Ewenczyk C, et al. The locus coeruleus/subcoeruleus complex in rapid eye movement sleep behavior disorders in Parkinson's disease: a 3T MRI study. Brain 2013;136:2120-2129.

21. Goetz CG, Tilley BC, Shaftman SR, et al. Movement Disorder Societysponsored revision of the Unified Parkinson's Disease Rating Scale (MDS-UPDRS): scale presentation and clinimetric testing results. Mov Disord 2008;23:2129-2170. 22. Hoehn MM, Yahr MD. Parkinsonism: onset, progression and mortality. Neurology 1967;17:427-442.

23. Johns MH. A new method for measuring daytime sleepiness: the Epworth Sleepiness Scale. Sleep 1991;14:540-545.

24. Iber C, Ancoli-Israel S, Chesson A, Quan S. The AASM Manual for the Scoring of Sleep and Associated Events: Rules, Terminology and Technical Specifications, 1rst Ed. Westchester, IL: American Academy of Sleep Medecine, 2007.

25. Postuma RB, Lanfranchi PA, Blais H, Gagnon JF, Montplaisir JY. Cardiac autonomic dysfunction in idiopathic REM sleep behavior disorder. Mov Disord 2010;25:2304-2310.

26. American Academy of Sleep Medicine. The international Classification of Sleep Disorders, 3rd edition. Darien, IL: American Academy of Sleep Medicine,, 2014. 27. Merino-Andreu M, Arnulf I, Konofal E, Derenne JP, Agid Y. Unawareness of naps in Parkinson's disease and in disorders with excessive daytime sleepiness. Neurology 2003;60:1553-1554.

28. De Cock VC, Vidailhet M, Leu S, et al. Restoration of normal motor control in Parkinson's disease during REM sleep. Brain 2007;130:450-456. 
29. Sixel-Doring F, Trautmann E, Mollenhauer B, Trenkwalder C. Associated factors for REM sleep behavior disorder in Parkinson disease. Neurology 2011;77:1048-1054.

30. Oudiette D, Leu S, Pottier M, Buzare MA, Brion A, Arnulf I. Dreamlike mentations during sleepwalking and sleep terrors in adults. Sleep 2009;32:16211627.

31. Iranzo A, Santamaria J. Severe obstructive sleep apnea/hypopnea mimicking REM sleep behavior disorder. Sleep 2005;28:203-206.

32. Kotagal V, Albin RL, Muller ML, et al. Symptoms of rapid eye movement sleep behavior disorder are associated with cholinergic denervation in Parkinson disease. Ann Neurol 2012;71:560-568.

33. Limousin N, Konofal E, Karroum E, et al. Restless legs syndrome, rapid eye movement sleep behavior disorder, and hypersomnia in patients with two parkin mutations. Mov Disord 2009;24:1970-1976.

34. Tuin I, Voss U, Kessler K, et al. Sleep quality in a family with hereditary parkinsonism (PARK6). Sleep Med 2008;9:684-688.

35. Lo Coco D, Caruso G, Mattaliano A. REM sleep behavior disorder in patients with DJ-1 mutations and parkinsonism-dementia-ALS complex. Mov Disord 2009;24:1555-1556.

36. Gan-Or Z, Girard SL, Noreau A, et al. Parkinson's disease genetic loci in rapid eye movement sleep behavior disorder. Journal of molecular neuroscience : MN 2015;56:617-622. 